\title{
Departing Thoughts from IJTMB's Practice \& Education Section Editor: Critical Inquiry, Dichotomy vs. Continuum, and Improving TMB Discourse
}

\author{
Niki Munk, PhD, LMT \\ P\&E Section Editor, IJTMB \\ Department of Health Sciences, School of Health and Rehabilitation Sciences, \\ Indiana University - IUPUI, Indianapolis, IN, USA
}

For the past three years, I have had the great privilege of serving as Editor of first the Practice Section alone and then also the Education Section of the International Journal of Therapeutic Massage and Bodywork (IJTMB), a journal unique in its mission to link the complementary components of research, education, and practice for the therapeutic massage and bodywork (TMB) field. IJTMB's mission is what drew me to the role of editor. My career and scholarly work includes, or has included, each component. Along the way, I have focused a lot of my energy and voice to encourage other TMB professionals to become more knowledgeable about, and involved in, the TMB component that seems to get the least "love": research. ${ }^{(1-4)}$ I have so enjoyed facilitating the important contributions of others from the TMB field as they have submitted to, and published in, IJTMB during my tenure. By going through the process of scientific dialogue, these contributors have navigated a challenging yet rewarding journey; congratulations and "thank you" to all involved: authors, mentors, reviewers, and fellow editors!

In preparation for my final editorial, I have reflected on the diverse and valuable work included within and between the components of TMB research, education, and practice and the challenges each - and our field as a whole - faces. One challenge is that TMB's place in the various health and wellness-related fields is nebulous. Despite the increased attention paid to the benefits and use of TMB as practiced by TMB practitioners, ${ }^{(5-10)}$ its tenuous situation may stem in part from its position within several other health-related fields' scopes of practice. It stands to reason that a unified "voice" from the TMB field could help solidify a distinct position in the realm of health and wellness care. While increased awareness and visibility is advantageous for the TMB field, the increased presence of research-related activity seems to fuel a contentious debate in the TMB field, pitting the views of various "factions" against each other. As TMB's place among health and wellness continues to be determined, faction disputes may become an additional challenge to the TMB field, and one we bring upon ourselves.
There are fissures within the TMB field that threaten to irrevocably separate TMB components by approach: one side aligning with a more analytical, "research is important for every stakeholder in the field and should be valued and utilized to make the field stronger" perspective, whilst the other aligns with a more intuitive, "research isn't needed, we know what we know and we know it works" perspective. However, few arguments are simple dichotomies. Many TMB professionals (myself included) consistently integrate aspects from analytical and intuitive perspectives and find themselves somewhere on a continuum regarding topics of debate, supporting points from each extreme. Regardless of whether some formal distinction is made between TMB "factions", genuine mutual respect and regard needs to be extended from any given "side" to honor the value and protect the integrity of the other(s) if any of us are to practice what we as TMB professionals purport to preach: authenticity, truth, and integrity. As thesis for my final Editorial, I would like to assert that a) each TMB component (research, education, and practice) is crucial for the field's success, b) each faction within and between TMB components should cultivate respectful dialogue with the others, and c) if embraced as a true pursuit, critical inquiry could be a unifying link within and between each faction aligned or not with any particular TMB component.

At the core of critical inquiry is the search for truth. Critical inquiry has been described as "the process of gathering and evaluating information, ideas, and assumptions from multiple perspectives to produce well-reasoned analysis and understanding, [leading to] new ideas, applications and questions.",(11) I find critical inquiry resonates with responsible, beneficent, and ethical conduct in general, and seems to be a practice all TMB professionals can appreciate and value. However, the extreme views of opposing factions within the TMB field seem to demonstrate disregard of critical inquiry. As one who works within each TMB component (research, education, and practice) and who often stands with a foot on both sides of various faction debates, I feel compelled to articulate 
the argument and behavior flaws from dichotomous extremes through the lens of critical inquiry.

Those from a more analytical "precise measurement and reporting" side could be more supportive of the value, passion, and legitimate place of those from the more intuitive "the work cannot conform to a set of criteria" side. All need to remember that it is mainly upon the backs of the latter that TMB was brought to the mainstream public: traditional healers from various cultural backgrounds, practitioners of alternative healing systems, and those who resonated with the universality and power of touch for health and healing in general. It is a shame when analytical arguments, purporting to value scientific method and evidence, sometimes forget that current technology may still be unable to provide the measure of a phenomenon. The passage of time is often needed along with specific collaborations of information, talent, and expertise for scientific revolutions to occur and paradigms to shift. ${ }^{(12)}$ There are countless examples of yesterday's mysticism becoming today's science. Devaluing, disregarding, or ridiculing those who earnestly seek to measure and understand unexplainable phenomena goes against the intent of critical inquiry and science while eroding the integrity of truth's pursuit. Such approaches serve to polarize those concerned that what they do cannot be valued through current scientific process. This can lead us to forget the evidence that training and experience affects practice outcomes, the complexity and newness of whole/complex systems research, and the extremely limited funding for comparative effectiveness and other real-life trial designs that can test TMB claims that initially seem "unresearchable".

Conversely, those from a more intuitive "the integrity of the work will be diminished by conformity" side could be more supportive of the value, passion, and necessity for the overall TMB field benefits from the more analytical "we must understand how and why TMB works and apply it effectively and efficiently" side as well. The value of research and evidence-informed practice has a rich history leading to important health care breakthroughs, often met with contentious initial resistance. Examples of such breakthroughs include washing hands, sterilization, separation of the sick and the well, basic nutrition, anesthesia, antibiotics, and countless other interventions and practices that modern society takes for granted. It is a shame when those who hold to authenticity, honesty, and the journey of personal healing turn away from, deny, or disregard legitimate evidence that may counter or challenge their held belief or force their reconsideration of how and why something is the way it is. The understanding of how and why things are the way they are develops from the best a priori/a posteriori (things we have been told/experienced) information available. Fixation of belief through simple a priori/a posteriori means is inherently limited by varying degrees based on exposure and experience.
It was because of this limitation that "father of pragmatism," C. S. Peirce, charged the method of science (which encompasses and expands upon both a priori and a posteriori methods) as crucial for determining truth. ${ }^{(13,14)}$ Honest consideration of the evidence upon which belief is based requires the recognition of evidence weaknesses, as well as understanding why others may not adopt or subscribe to a particular belief. That is not to say pursuit of belief despite weak evidence is unimportant or futile. Indeed, it is from similar determined pursuit of the unexplained, through dedication to critical inquiry, that some of the most amazing scientific discoveries originated! TMB professionals practice and value critical inquiry through treatment development and application every day, and are poised to make significant contributions to practice-based evidence if only they take the next step and earnestly join the scientific dialogue. Incorporating authentic critical inquiry from both analytical and intuitive perspectives could well serve all from the TMB field and perhaps help to lessen the intensity of disagreement in our professional discourse.

In closing, I'd like to offer the consideration of a framework from which benefit may stem if applied to how various TMB defining aspects are considered. I mentioned before that rare is the situation in which dichotomy is apropos and hinted that continuums likely provide a more accurate reflection of reality. Researchers have struggled with this in relation to study designs, particularly when considering whether the intent is to examine an intervention's efficacy (the extent to which something works under ideal situations - explanatory) or effectiveness (the extent to which something works under usual circumstances - pragmatic). ${ }^{(15)}$ In 2009, Thorpe and colleagues published the PRECIS model ${ }^{(16)}$ which illustrated the series of continuum components (e.g., participant characteristics, intervention flexibility, and practitioner expertise) that determine the extent to which a trial is explanatory or pragmatic. In the PRECIS model, each continuum component serves as a spoke in the overall PRECIS "wagon wheel." When a trial design is assessed via the PRECIS model, a clear and visual, quantified picture is presented of what the assessed trial is regarding its design. ${ }^{(7,17-20)}$ Perhaps the TMB field could use a PRECIS model type approach to explore the diversity within the field regarding how TMB is used, accessed, and described. By moving away from dichotomous delineations, the field may find a clearer and more accurate way to describe and consider itself, perhaps lessening the "heat" of contentious debate.

I sign off from my post on the Editorial Board of IJTMB looking forward to the constructive conversation I hope this Editorial provokes. While I am stepping away from this role, my research contribution to the TMB field will continue. I look forward to seeing everyone at various TMB-related meetings and functions and to the continued critical dialogue that 
is so important to the development and continuation of the TMB field.

Please accept my warmest regards, and may your current and future inquiries all be critical!

\section{ACKNOWLEDGMENTS}

I would like to acknowledge Executive Editor Antony Porcino for the generous time he spent with me during this editorial's refinement. I value and appreciate his critical insight and feedback which challenges and benefits my critical thinking and writing clarity. I would also like to acknowledge Editorin-Chief Karen Boulanger for the conversation we had during this editorial's early development which sparked my interest to develop a reflection on critical inquiry regarding our field.

\section{COPYRIGHT}

Published under the CreativeCommons AttributionNonCommercial-NoDerivs 3.0 License.

\section{REFERENCES}

1. Munk N, Reynolds M, Werner R, narrators. Research Perch 1-24 [audio \& video podcasts]. Available at: http://www. massagetherapyfoundation.org/research-perch/

2. Lowe W, Munk N, Porcino A. Introducing IJTMB's Trigger Points: Topical dialogue amongst therapeutic massage \& bodywork practitioners and educators. Int $J$ Ther Massage Bodywork. 2014;7(2):1-2.

3. Munk N. Case Reports: A meaningful way for massage practice to inform research and education. Int J Ther Massage Bodywork. 2013;6(3):3-5.

4. Munk N, Boulanger K. Adaptation of the CARE guidelines for therapeutic massage and bodywork publications: efforts to improve the impact of case reports. Int $J$ Ther Massage Bodywork. 2014;7(3):32-40.

5. Cherkin DC, Sherman KJ, Kahn J, Wellman R, Cook AJ, Johnson E, et al. A comparison of the effects of 2 types of massage and usual care on chronic low back pain: a randomized, controlled trial. Ann Intern Med. 2011;155(1):1-9.

6. Cook AJ, Wellman RD, Cherkin DC, Kahn JR, Sherman KJ. Randomized clinical trial assessing whether additional massage treatments for chronic neck pain improve 12- and 26-week outcomes. Spine J. 2015;15(10):2206-2215.

7. Elder WG, Munk N. Using the Pragmatic-Explanatory Continuum Indicator Summary (PRECIS) model in clinical research: application to refine a practice-based research network (PBRN) study. JABFM. 2014;27(6):846-854.
8. Munk N, Stewart K, Love MM, Carter E, Elder WG. The intersection of massage practice and research: community massage therapists as research personnel on an $\mathrm{NIH}$-funded effectiveness study. Int J Ther Massage Bodywork. 2014;7(2):10-19.

9. Perlman AI, Ali A, Njike VY, Hom D, Davidi A, Gould-Fogerite $\mathrm{S}$, et al. Massage therapy for osteoarthritis of the knee: a randomized dose-finding trial. PLoS One. 2012;7(2):e30248.

10. Sherman KJ, Cook AJ, Wellman RD, Hawkes RJ, Kahn JR, Deyo RA, et al. Five-week outcomes from a dosing trial of therapeutic massage for chronic neck pain. Ann Fam Med. 2014;12(2):112-120.

11. Critical Inquiry (AFCO 101) [course description]. Aiken, SC: University of South Carolina Aiken; [n.d.]. Available from: http://web.usca.edu/academic-affairs/general-education/ critical-inquiry.dot. Accessed January 11, 2015.

12. Kuhn TS. The Structure of Scientific Revolutions. Chicago, IL: University of Chicago Press; 1962.

13. Peirce CS. The fixation of belief. Popular Science Monthly. Nov. 1877;1-12.

14. Buchler J. The Philosophy of Peirce: Selected Writings. N.Y.: Routledge; 2014.

15. Gartlehner G, Hansen RA, Nissman D, Lohr KN, Carey TS. Criteria for Distinguishing Effectiveness from Efficacy Trials in Systematic Reviews. Technical Reviews, No. 12. AHRQ Publication No. 06-0046. Rockville, MD: Agency for Healthcare Research and Quality; 2006.

16. Thorpe KE, Zwarenstein M, Oxman AD, Treweek S, Furberg $\mathrm{CD}$, Altman DG, et al. A pragmatic-explanatory continuum indicator summary (PRECIS): a tool to help trial designers. $J$ Clin Epidemiol. 2009;62(5):464-475.

17. Koppenaal T, Linmans J, Knottnerus JA, Spigt M. Pragmatic vs. explanatory: an adaptation of the PRECIS tool helps to judge the applicability of systematic reviews for daily practice. J Clin Epidemiol. 2011;64(10):1095-1101.

18. Glasgow RE, Gaglio B, Bennett G, Jerome GJ, Yeh HC, Sarwer $\mathrm{DB}$, et al. Applying the PRECIS criteria to describe three effectiveness trials of weight loss in obese patients with comorbid conditions. Health Ser Res. 2012;47(3 Pt 1):1051-1067.

19. Riddle DL, Johnson RE, Jensen MP, Keefe FJ, Kroenke K, Bair MJ, et al. The Pragmatic-Explanatory Continuum Indicator Summary (PRECIS) instrument was useful for refining a randomized trial design: experiences from an investigative team. J Clin Epidemiol. 11// 2010;63(11):1271-1275.

20. Bratton DJ, Nunn AJ, Wojnarowska F, Kirtschig G, Sandell A, Williams HC. The value of the pragmatic-explanatory continuum indicator summary wheel in an ongoing study: the bullous pemphigoid steroids and tetracyclines study. Trials. 2012;13:50.

Corresponding author: Niki Munk, $\mathrm{PhD}, \mathrm{LMT}$, Department of Health Sciences, School of Health and Rehabilitation Sciences, Indiana University - IUPUI, Indianapolis, 1140 W. Michigan St., IN, USA 46202 E-mail:nmunk@iu.edu 